\title{
Negative pressure wound therapy with instillation (NPWTi): Current status, recommendations and perspectives in the context of modern wound therapy.
}

\author{
Adam Bobkiewicz, Adam Studniarek, Michał Drews, Tomasz Banasiewicz
}

\section{REVIEW}

\begin{abstract}
Introduction of negative pressure wound therapy (NPWT) revolutionized the conception of wound healing. Currently, increasing number of studies confirmed the high efficiency of this therapy in many clinical scenarios. Moreover, some innovations have been introduced in recent years to improve the management of complex and chronic wounds. NPWT with instillation (NPWTi) combines traditional NPWT with application of topical irrigation solutions within the bed of the wound. Bioburden reduction, decreases time to wound closure, promotes granulation and tissue formation. Fewer operative visits are required when using NPWTi compared to standard NPWT. However, there are still questioned aspects of the NPWTi and thus its superiority over standard NPWT has not been fully indicated. Moreover, based on current studies no firm conclusions have been taken concerning the type of instilled solution preferably used, range of dwell- time phase, range of negative pressure and others. The main goal of the publication is to overview and summarize the current state of art concerning NPWTi. Moreover, mechanisms of action, review of the most commonly used instilled solutions are discussed and clinical evidence of NPWTi are described.
\end{abstract}

Keywords-NPWT, instillation,

\section{INTRODUCTION}

T HE introduction of negative pressure wound therapy (NPWT) in the late 1980s simultaneously in the United States and Germany revolutionized the management of complex and chronic wounds $1+3$

Its initial clinical indication was designed for chronic wounds of lower extremity such as leg ulcers, decubitus ulcers and traumatic wounds after open fractures. Very quickly the indication for NPWT was extended to other varying wounds with different underlying pathologies.

Because of excellent results of NPWT and the progress in both basic science research and clinical trials regarding NPWT,

Manuscript received 18.03.2016; revised 28.03.2016. This work did not receive any financial support. Authors declare no conflict of interest.

Author affiliations: Department of General, Endocrinological Surgery and Gastroenterological Oncology Poznan University of Medical Sciences, Poland , (AB, AS, MD, TB)

*Correspondence to: Adam Bobkiewicz, MD, Department of General, Endocrinological Surgery and Gastroenterological Oncology Poznan University of Medical Sciences, Przybyszewskiego 49, 60-355 Poznan, Poland. Phone: +48618691 122; fax: +48618691684; e-mail: bobofon007@gmail.com this therapy has become a widely accepted and common therapeutic modality. Currently, there is a wide spectrum of indications for NPWT including open fractures, amputation wounds, sternal wound infections, enterocutaneous fistulas, open abdomen management, abdominal wound dehiscence, vascular bypass site infection and many others $[4$

In 2003, Kinetic Concept Inc. introduced a first commercialized system of NPWT instillation (NPWTi): V.A.C Instill Wound Therapy. A new method of negative pressure wound therapy combined the benefits of standard NPWT with an introduction of incorporated, controlled and periodic instillation of topical solution to the wound bed. The mechanism of action allows for the delivery of instilled fluid to the bed wound facilitating a removal of cellular debris, exudate and inflammatory molecules that may impair the processes of proper wound healing. Moreover, NPWTi decreases the bacterial bioburden within the wound and influences the reduction of biofilm formation.

Nowadays, NPWTi has been commonly applied to numerous clinical scenarios. In 2013, following an expert panelists' discussion, the first International Consensus Guidelines was created to establish the principles for NPWTi. ${ }^{[7}$ Although some recommendations and guidelines have been reported before, there are still number of questions concerning NPWTi. Additionally, there is an increased list of publications regarding NPWTi including different type of instilled solutions, setting parameters such as instillation time, dwell time as well as time of NPWT. Therefore, there is a constant debate in regards to the most accurate recommendations.

The majority of publications concerning NPWTi are expert opinions, case reports or case series therefore it is difficult to establish evidence-based conclusions.

In this review, we focused on the current state of art regarding NPWTi: present indications, types of administered instilled solutions and potential problems with the utility of NPWTi were highlighted. We analyzed other instilled solutions used in NPWTi that were previously evaluated by other authors and are currently not firmly recommended. Additionally, we described the mechanisms of action for the purpose of highlighting the principles of NPWTi and thus showing the 
potential superiority to the standard NPWT.

We believe that the presented detailed review may help in optimal selection for NPWTi settings for specific clinical indications and scenarios. Moreover, we hope this work may increase researchers' knowledge and improve the quality of designed experimental studies regarding ongoing research in the field of NPWTi.

\section{MEChANISM OF ACTION}

The mechanism of action for NPWTi remains the same in regards to the standard NPWT and is the basis for successful outcomes of NPWTi. The applied negative pressure within the surgical wound indicates its multi-dimensional action that positively influences the wound healing process.

The increase of local blood flow influences an enhanced collagen synthesis and promotes mechanisms that stimulate angiogenesis. NPWTi also leads to a decreased local tissue edema, lowers the number of bacteria within the wound and removes inhibitory agents. The use of NPWT positively affects tissue granulation process and maintains a moist wound environment. Additionally, NPWT reduces lateral tension of the wound edge, positively influences the wound contraction and supports a proper wound edge vascularity $[-[-10$

\section{CEllular AND MOLECUlar CHANGES}

Both in vitro and in vivo models showed, that the administration of reticulated open-cell foam (ROCF) generates microstrain at the cellular level which has a direct influence on the elevation of proliferating cells within the wound and enhances vascularity 11,12

At the cellular level, a mechanical strain generated with negative pressure stimulates sensory cells to molecular changes within cells 13 Gravity and hemodynamic forces, as constituents of NPWT, significantly influence the improvement in microenvironmental conditions of the wound bed resulting in an enhanced wound healing! 14 Although, some mechanisms of action at the cellular level are still unknown, the conception of cellular mechanotransduction seems to accurately describe the mechanisms of alteration and enhancement of cellular properties with the usage of NPWT through the direct use of administered negative pressure.15

In vitro studies demonstrated that the administration of negative pressure wound therapy positively influences the function and activity of fibroblasts!11 The use of NPWT stimulates proliferation, production and remodeling of fibroblasts, extracellular matrix, as well as increases growth factors production.11 16 The results of in vitro studies were confirmed by in vivo results. Scherer et al. confirmed that cell proliferation expressed as a percentage of Ki67-positive nuclei was significantly greater in NPWT group compared to other groups in mice model 11

\section{BIOFILM}

It has been presented that NPWTi significantly influences the reduction of biofilm composed of varying microorganisms within the wound, which is considered one of the main reasons for impaired wound healing.
Based on research studies with an animal model and clinical practice, it was stated that the presence of microorganisms within the wound, their influence on the wound bed, quick replication and tendency to form colonies result in biofilm formation. Bacteria is the most common reason for biofilm formation, however usually within a wound there is a complex biofilm formation by bacteria, fungi and protozoa embedded in a self-produced extracellular matrix of polysaccharides or other extracellular polymeric substance (EPS), cellular debris and exudates. 17

Consequently, providing a substance to the wound, should by definition remove not only the exudates and cellular debris but also influence the destruction and removal of biofilm bacteria which is a basis for its success.

Mechanical debridement, reduction of biofilm and autolytic mechanisms are considered the most important components of NPWTi action and they are key elements emphasizing the advantage of NPWTi over the standard NPWT! 18

The above-mentioned concept and the need for modification of systems and treatment therapy of chronic wounds are associated with the current state of the art, indicating that microbial biofilm is one of the crucial factors impairing wound healing 19 Phillips et al. analyzed based on an animal model various antimicrobial solutions on Pseudomonas aeruginosa biofilm. $\stackrel{22}{ }$ Using seven solutions with periodic NPWT instillation, they compare their efficacy versus NPWT alone and NPWT with saline solution. Using NPWT alone (no instillation used), there was no statistical significance in comparison to the untreated control group even though the reduction in total CFUs was observed. All experimental groups using both antimicrobial solutions and saline showed statistical significance in the reduction of CFUs compared to the untreated group. However, in authors' opinion, in the saline group the reduction in CFUs was rather associated with mechanical removal than other potential mechanisms acting on the bacteria's biofilm. Comparing the antimicrobial solution groups with the saline groups, all of them except one (Ssolution) showed statistical significance in reduction of CFUs.

Conventionally used lavage, which was initially considered an important element of wound cleansing, has an increased risk of bacteria dispersion within the wound bed as well as beyond the wound. Allen et al. based on the wound models compared the standard lavage technique and NPWTi and its influence on the degree of bacterial dispersion and crosscontamination using ex-vivo model with fluorescent bacterial particles inoculation. ${ }^{23}$ Both low-pressure lavage and NPWTi showed comparable effectiveness of wound cleansing (debris reduction $>90 \%$ ). However comparing tissue damage, based on three-dimensional photography, more severe tissue damage was revealed in NPWTi treatment group $(\mathrm{P}<0.05)$. The most important is the fact of no evidence for cross-contamination in NPWTi. Gabriel et al. comparing bacterial bioburden reduction in NPWTi group and the control group (standard wound-care therapy) showed statistical significance in the time required to decrease bacterial bioburden ( $6.0 \pm 1.5$ versus $25.9 \pm 6.6$ days respectively)! 18

It is important to note that regardless of the type of the negative pressure therapy, settings, type of instilled fluid, the 
crucial aspect is initial debridement of the wound. Appropriate debridement is necessary to eliminate poorly vitalized and necrotic tissue, all foreign bodies within the wound bed as well as any excessive cellular debris. Currently, there are numerous methods for debridement including lavage, autolytic agents, ultrasound, chemicals and enzymes or surgical procedures. .24 Regular debridement also plays an important role in bacterial biofilm reduction. 25 26

\section{TISSUE GRANULATION}

Leung et al. comparing the standard NPWT versus NPWTi analyzed the acceleration of wound granulation in porcine model. Using the NPWT with instillation and normal saline in 4 cycles of instillation per day (dwell times: 5 or 60 minutes), they demonstrated statistically significant wound filling and collagen deposition within the granulated tissue within a bed wound ${ }^{27}$ Brinkert et al. in a prospective study evaluated the effect of NPWTi used in different clinical scenarios. ${ }^{28}$ A total of 131 patients were enrolled to either NPWTi group as the primary method of treatment $(n=85 ; 64,9 \%)$ or received NPWTi after a failed standard NPWT therapy $(n=46 ; 35,1 \%)$. Granulation of the wound bed was increased in NPWTi group versus standard NPWT. Moreover, significant reduction of wound volume was also shown in NPWTi versus standard NPWT. Dead space of the wound as well as any undermined cavities were granulated more rapidly in NPWTi in comparison to the standard NPWT. Lessing et al. investigated the influence of different application of standard NPWT and NPWTi on granulation of the wound in porcine model.29 NPWTi with saline ( 5 minutes of dwell time every 2,5 hours, negative pressure $-125 \mathrm{mmHg}$ ) and various settings of standard NPWT (intermittent, continuous, dynamic) were applied on dorsal excisional wound for 7 days. At the time of end point, tissue samples were taken for histological examination. In NPWTi group granulation thickness $(p<0,05)$, greater reduction of wound volume $(\mathrm{p}<0,05)$ and higher filling rate of the wound $(\mathrm{p}<0,05)$ were statistically significant compared to the standard NPWT.

\section{WOUND DRESSINGS}

The proper application and arrangement of negative pressure within the wound dressing is guaranteed with the use of reticulated open-cell foam (ROCF). The most commonly used foams on the market are: ROCF- G (V.A.C. $\cap$ GranuFoam $^{\mathrm{TM}}$ Dressing, KCI USA, Inc, San Antonio, TX) oraz ROCF-V (V.A.C. VeraFlo Cleanse ${ }^{\mathrm{TM}}$ Dressing System, KCI USA, Inc.). Although pore sizes are comparable in both types of dressings, the different chemical composition of dressings leads to the fact that physical and chemical properties are different in both cases of wound dressings. Therefore, the interactions between the dressing and a wound are also different. ROCF-G is composed of polyether- based polyurethane foam, whereas ROCF$\mathrm{V}$ is made of polyester-based polyurethane foam. ROCF-V is less hydrophobic than ROCF-G, which allows for an easier adherence and distribution of instilled fluid within the wound.

It was confirmed that the less hydrophobic property of ROCF dressing is, the more affinity of fluid adherence within the dressing is observed. 30 Moreover, it is easier to drain the instilled fluid with wound exudate and cellular debris outside the wound. The better susceptibility of ROCF-V for preserving the fluid within the wound dressing also allows for a lower risk of pooling the fluid beneath the dressing and outside the wound, which may contribute to an incidence of a leak and unsealing of the wound dressing ${ }^{31}$ Scanning electron microscopy images showed similar pore size and structure of both ROCF-G and ROCF-V $\stackrel{32}{ }$ Comparable results were presented by Lessing et al. ${ }^{30}$ The mean value of pore size was estimated to be $400 \mu \mathrm{m}$ to $600 \mu \mathrm{m}$ in both ROCF-G and ROCF-V. Lessing et al. using scanning electron microscopy compared mechanical properties of ROCF-G and ROCF-V regarding tension, compression and tearing properties. $\stackrel{30}{ }$ Moreover, the properties of individual foams were analyzed in both wet and dry conditions. Wet ROCF-V showed statistically better properties under tensile and tear condition than ROCF-G, in both wet and dry circumstances. Comparing fluid distribution, ROCF-V showed better capabilities of accumulating fluid versus ROCF-G. Based on histological analysis, ROCF-V showed increased granulation within the wound in comparison to ROCF-G after 7 days of NPWTi or NPWT alone $(\mathrm{P}<0.05)$.

It is important to note that both dressings ROCF-V and ROCF-G present characteristic to all polymers, a type of plasticizing effect and hydrolytic degradation due to the interaction with instilled fluid; however, ROCF-V has shown weaker above-mentioned properties 30

\section{CONTINUOUS- VERSUS PERIODIC- INSTILLATION}

Although NPWTi has been used worldwide in many clinical scenarios, there are no firm conclusions and recommendations regarding the optimal type of instillation or a range of dwell time and amount of instilled fluid.

Rycerz et al. described a wound model for the purpose of assessment of optimal fluid distribution within a wound based on two different methods of fluid administration (stained with methylene blue) $\frac{33}{3}$ Using agar-based model, they studied the impact of continuous- and periodic- instillation on two types of designed wounds: 1) a simple wound and 2) a complex tunneled wound. In the model using continuous instillation, $30 \mathrm{ml}$ of fluid/ hour throughout $3,5 \mathrm{~h}$ was administered using the negative pressure of $-125 \mathrm{mmHg}$. On the other hand, in the model using periodic instillation, $75 \mathrm{ml}$ of fluid in a simple wound model and $120 \mathrm{ml}$ of fluid in a complex wound model were administered and held for $10 \mathrm{~min}$ and later repeated $(-125 \mathrm{mmHg}$ was set up). Comparing the two types of therapies, an isolated penetration of the fluid within the wound bed in both simple and complex wound was observed in continuous instillation, whereas a regular pattern of wound bed staining was revealed in periodic instillation. Despite the fact that in the above-mentioned study they demonstrated better administration parameters of instillation in the case of periodic instillation, according to some studies the efficiency of continuous instillation was also proven. Independently Lessing et al. and Scimeca et al. demonstrated the effectiveness of continuous instillation even though both used different instilled fluids: saline solution and doxycycline, respectively 30.34 
Argenta and Morykwas presented the benefits resulting from the use of intermittent therapy in standard NPWT, emphasizing the better perfusion of both the wound tissue and surrounding tissues. 35 The element of intermittent therapy in NPWTi is unequivocally part of the administered therapy composed of instilled phase with the following dwell time phase, and then with a formation and maintenance of negative pressure. However, it seems that both the benefits of instilled solution and the intermittent pauses of active negative pressure positively influence the effects of treatment with NPWTi.

\section{InSTILLATION SOLUTIONS}

Based on recent International Consensus Guidelines from 2013, the following instillation solutions were approved as efficient for the purpose of instillation: Lavasept $(\mathrm{R}$ (polyhexanide $0.04 \%$ ), Prontosan $\AA$ (polyhexanide $0,1 \%$ with betaine) and Microcyn/Dermacyn $\AA$ (hypochlorous acid solution) ${ }^{7}$ The final consensus was established when more than $80 \%$ of expert panelists agreed on the appropriate efficiency of analyzed instillation solution.

However, there are some limitations to these agreements. Firstly, the recommendations are based on a personal opinion of twelve expert panelists' agreement. Secondly, various studies with different methodologies were included into the consensus such as prospective, randomized, comparative and controlled studies leading to a creation of a bias in the recommendations.

Based on the same consensus other solutions were also evaluated. Despite the fact that they did not meet the agreement criteria, it was stated that other instillation solutions may still be considered in particular clinical scenarios. However, ongoing research and clinical trials are required to confirm its efficiency.

Below, we present the most common instillation solutions used in NPWTi. The mechanism of action of a particular solution was briefly described. Additionally, we indicated their potential disadvantages and described both preclinical and clinical studies regarding the utility of instillation solutions. The most common instilled solutions are summarized in Table 1 .

\section{A. Isotonic solutions}

Leung et al. by comparing NPWT with normal saline instillation versus standard NPWT in porcine model showed a statistical significance in collagen deposition and tissue granulation within the wound in the experimental group with NPWTi. ${ }^{27}$ Kim et al. conducted a prospective randomized study comparing NPWT instillation with normal saline and antiseptic solution $(0,1 \%$ polyhexanide plus $0,1 \%$ betaine) There was no statistical significance in any of the analyzed parameters (a number of operative visits, a length of hospital stay, a wound healing rate and a wound healing rate within 30-day follow-up) in comparison to two cohorts of patients. However, the time to final surgical procedure was statistically shorter in the normal saline group $(\mathrm{p}=0,038)$. In authors' opinion the effectiveness of normal saline utility in NPWTi is comparable to this antiseptic solution.
Brinkert et al. showed a high rate of wound closure in $98 \%$ of patients using NPWTi with normal saline in case series of 131 patients. ${ }^{28}$ However, this study has one important limitation. Almost half of the patients $(48,8 \%)$ received standard NPWT prior to implementation of NPWTi. Thus the firm conclusion suggesting NPWTi as a more efficient therapy is questionable. Fluieraru et al. in a retrospective case series study proved the efficiency of NPWTi with saline instillation in patients who previously did not recover under the standard therapy as well as in patients with chronic complex wound with no previous NPWT treatment ${ }^{44}$ In general, in 23 out of 24 patients tissue granulation was achieved and surgical wound closure was possible using either flaps or skin grafts treatment. Phillips et al. and Davis et al. independently proved in porcine model that the reduction of $\mathrm{P}$. aeruginosa bacterial bioburden is significantly lower using saline when compared to $0.1 \%$ polyhexanide and $0.1 \%$ betaine solution. 22.45

\section{B. Hypochlorite-based solutions}

1) Dakin's solution: The historical root for the utility of Dakin's solution goes back to the times of World War I. ${ }^{46}$ At the time of its development it was considered one of the most efficient bactericidal agents for combat injuries ${ }^{47}$ The main component of Dakin's solution is sodium hypochlorite. Dakin's solution is a slightly alkaline solution with the concentration of sodium hypochlorite ranging from $0,125 \%-0,5 \%$.

$0,5 \%$ Dakin's solution is termed "full strength" and it is the highest concentration of sodium hypochlorite which is well tolerated by the skin without any side effects. Consequently, $0,25 \%$ Dakin's solution is termed "half strength", whereas $0,125 \%$ is known as "quarter strength". Based on both in vitro and in vivo studies the efficiency of $0,125 \%$ Dakin's solution was confirmed against $\mathrm{S}$. aureus, $\mathrm{P}$. aeruginosa, E. coli and Enterococcus .48 The cost, availability and simplicity of using Dakin's solution makes it one of the most commonly used bactericidal solutions.

One of the raised controversies about Dakin's solution is its potential cytotoxicity. Kozol et al. confirmed the decreased viability and migration of neutrophils when Dakin's solution was used. ${ }^{52}$ Similar results were obtained independently by Heggers et al. and Lineaweaver et al., who studied the effect of Dakin's solution on fibroblasts $[51][53$ Both studies confirmed the dose- dependent effect of cytotoxicity on fibroblasts. Thus, the optimal concentration of Dakin's solution should be considered in respect to both: the bactericidal effect resulting in reduction of bacterial bioburden and the risk of alteration of the function of macrophages and leucocytes which are the crucial molecules acting in the inflammatory phase of wound healing.

2) Microcyn $\mathrm{R} /$ Dermacyn $\mathrm{R}$ : Microcyn is a solution composed of hypochlorous acid and sodium salt. Contained hypochlorous acid is similar to the one naturally occurring in humans. In in vitro model, Microcyn reduced the level of P. aeruginosa, E. coli and $\mathrm{S}$. aureus with a statistical significance $[54[55]$ Microcyn $\cap /$ Dermacyn $($ creates a moist woundcare therapy with the property of rehydration of the necrotic tissue and promoting autolysis. Goretti et al. compared Dermacyn and diluted povidone iodine in the management of 
Table I

THE MOST COMMON SOLUTIONS AND AGENTS USED IN NEGATIVE PRESSURE WOUND THERAPY WITH INSTILLATION

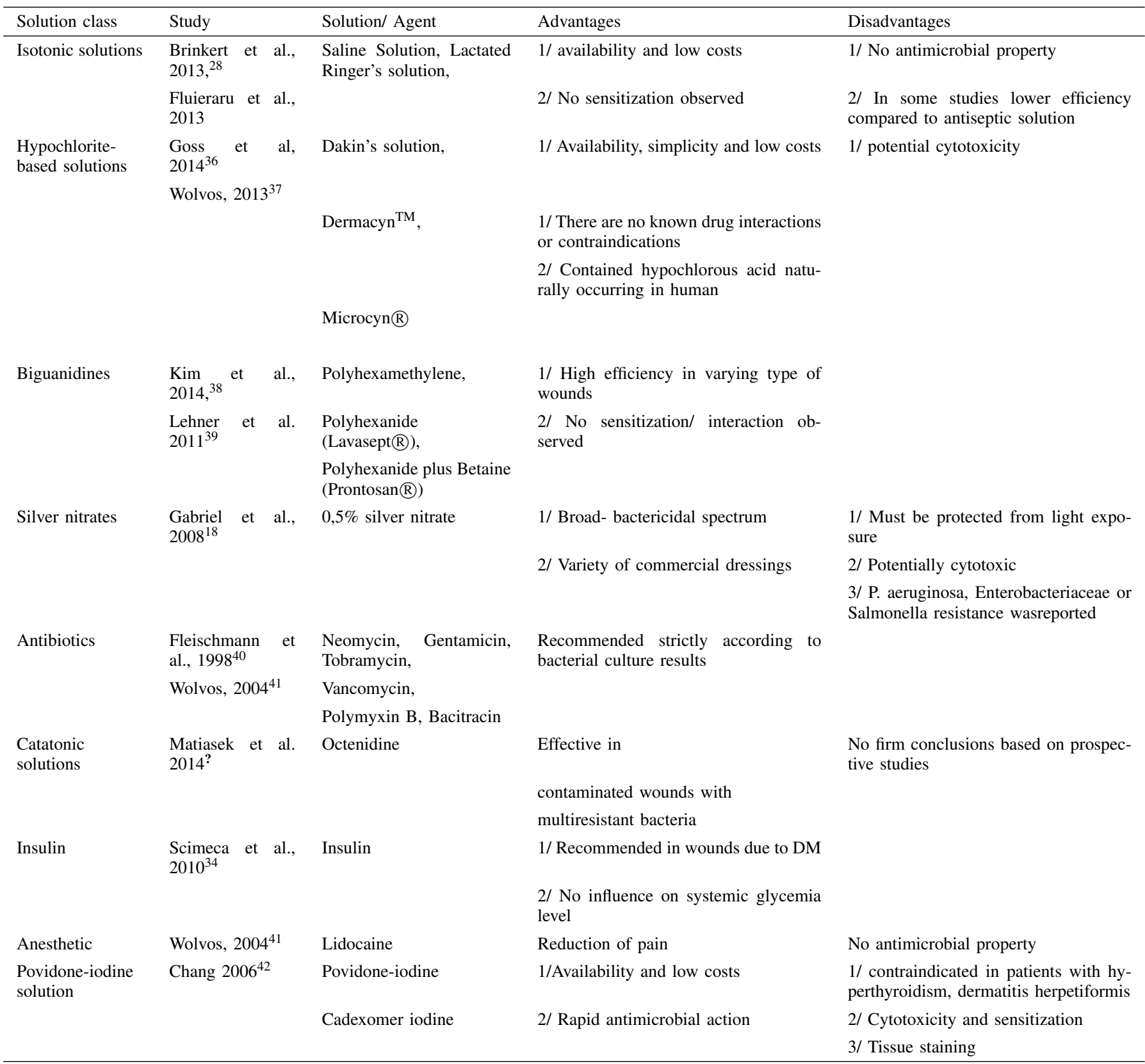

postsurgical infected ulcers of the diabetic foot ${ }^{56}$ Patients treated with Dermacyn presented significantly shorter healing time and a higher wound healing rate at 6 months. Landsman et al. evaluated the effect of Microcyn in the treatment of mildly infected diabetic foot ulcers ${ }^{[57}$ In comparison to the oral levofloxacin treatment group, Microcyn showed higher clinical success rate of treatment $(\mathrm{p}=0,033)$.

\section{Biguanidines}

1) Lavasept $\mathrm{R} /$ Prontosan $\mathrm{R}$ : Both Lavasept $\mathrm{R} /$ Prontosan $\mathrm{R}$ belong to the group of biguanides composed of polyhexamethylene biguanide. Additionally, Prontosan contains $0,1 \%$ betaine which has a comparable mechanism of action to surfactant, reducing the surface tension of a water solution allowing for a better penetration into the wound and to the bacterial biofilm.

Minnich et al. conducted an in vitro study using a solution of $0.1 \%$ polyhexanide and $0.1 \%$ of betaine. 58 reduction of 13 tested microorganisms was evaluated after 7, 14, and 28 days. Based on this study, the reduction of $\mathrm{S}$. epidermidis, P. aeruginosa, Serratia marcescens, C. albicans, S. aureus, vancomycin-resistant E. faecalis, P. mirabilis, E. coli, methicillin-resistant S. aureus, A. baumannii, E. cloacae, and E. faecalis was observed confirming the efficiency of $0.1 \%$ polyhexanide and $0.1 \%$ of betaine for microorganisms reduction. Romanelli et al. in a randomized controlled trial investigated the effect of the utility of polihexanide and betaine 
solution in patients with venous leg ulcers 5 Using a portable device measuring $\mathrm{pH}$ of the wound surface (which correlates with the level of bacterial burden), the authors confirmed the efficacy of polihexanide and betaine solution in reduction and stability of wound $\mathrm{pH}$ level in comparison to the control group $(\mathrm{p}<0,05)$. Hübner et al. evaluated the efficacy of 0.02 and $0.04 \%$ polyhexanide (polyhexamethylene biguanide, PHMB) against Pseudomonas aeruginosa SG81 biofilm in in vitro studies. ${ }^{?}$ Results achieved in the PHMB group was comparable to $0.1 \%$ chlorhexidine digluconate $(\mathrm{CHX})$ in regards to the amount of biofilm and bacterial metabolism in biofilms formed with Pseudomonas aeruginosa. Sibbald et al. conducted a multicenter, prospective, randomized clinical trial comparing the effectiveness of polyhexamethylene biguanide (PHMB) foam dressing and non-antimicrobial foam in the treatment of chronic wounds.

Bacterial bioburden was significantly reduced in PHMB foam group $(P=0,016)$. In addition, pain reduction was revealed as a statistically significant result at 2 weeks and at 4 weeks of the therapy in the group of PHMB management. Wound size in PHMB was also reduced in comparison to the non- antimicrobial foam.

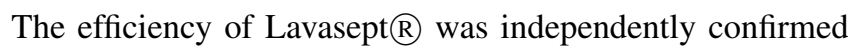
in clinical practice by a number of authors. Lehner et al.,

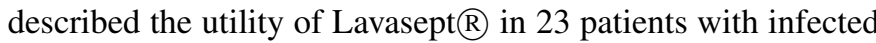
hip endoprosthesis (19 defined as an early infection and 4 as a late infection) ${ }^{39}$ The success rate was $84 \%$ in early infection, whereas in late infection $50 \%$ of success was reported. Thus in authors' opinion, NPWTi with Lavasept may be considered as a salvage management for infected endoprosthesis, especially in the early course of an infected hip endoprosthesis.

Köster evaluated the effect of using NPWT with Lavasept instillation in patients with an early periprosthetic infection following a knee endoprosthesis placement ${ }^{61}$ Only in one patient the implant needed to be removed, whereas in the majority of patients implant was preserved. NPWTi was continued from three to nine days. In all except one patient no infection was present at the time of follow-up (between 12 and 34 months postoperatively) confirmed by clinical, radiological and laboratory examination. In authors' opinion NPWTi with Lavasept reduces the number of surgical revisions, enhances the wound healing and reduction of infection leaving the knee implant in situ.

\section{Silver nitrate}

Silver nitrate possesses a potential property for a creation of somehow impermeable barrier against microorganisms' penetration in the bed wound ${ }^{62}$ However, in in vitro models it was observed that silver nitrate (but also nanocrystalline silver) exhibited a cytotoxic effect to cells, therefore playing a key role in the healing processes with the effect on leukocytes and macrophages, as well as fibroblasts and keratinocytes.?,53

In porcine model study presented by Wright et al., slightly different results were observed ${ }^{63}$ An increased apoptosis and decreased level of matrix metalloproteinase may potentially support the process of wound healing. The crucial element making the difference between in vitro and in vivo studies seems to have a potential to bind the ionic silver which is different in organic and inorganic constituents. Gabriel et al. did not observe any side effects of using silver nitrate for wound healing in the fifteen patients that they analyzed. Consequently, the instillation with silver nitrate was continued until the time of confirmed clearance of bacterial bioburden within the wound ${ }^{18}$ Statistical significance was revealed comparing the association between bacterial bioburden and the rate of wound closure in NPWTi group versus moist wound-care therapy $(\mathrm{p}<0,001)$.

\section{E. Povidone-iodine solution}

Povidone-iodine solution is a well- known disinfecting agent commonly used in trauma and surgical wounds. Optimal effectiveness of povidone-iodine solution was established with 1:100 dilution. However, solution with 1:10,000 dilution still presents bactericidal activity 64 P5 Potential disadvantages of povidone-iodine solution are tendency for an irritation to the applied site, cytotoxicity and staining of the tissues. Although in some in-vivo and animal studies the cytotoxicity was observed, these results were not confirmed in humans Povidone-iodine solution did not negatively influence bed wound healing.67. 68 Additionally, in comparison to other antiinfective agents (e.g. neomycin), the sensitization rate of povidone-iodine is relatively low 69 Chang et al. confirmed the efficiency of povidone-iodine solution in spinal surgery indicating a higher surgical site infection rate in the control group $(\mathrm{P}<0,05) \stackrel{42}{\underline{42}}$

\section{F. Insulin}

The potential positive effect of topical application of insulin on wound healing has been reported in basic science research. However, there are not many studies on insulin instillation in humans, therefore firm conclusions should not be taken. In both rat and rabbit studies, the application of insulin (or combined insulin-zinc therapy) promoted wound healing.?,70] Wilson et al. recommended the use of insulin solution for complex and chronic wounds resulting from diabetes mellitus including pressure ulcers and amputation site stumps ${ }^{71}$ Rezvani et al., investigated the use of topical insulin on wound healing in randomized, double-blind, placebocontrolled trial. ${ }^{72}$ The mean rate of wound healing was 46.09 $\mathrm{mm} 2 /$ day in the insulin treatment group and $32.24 \mathrm{~mm} 2 /$ day in the control group $(\mathrm{P}=0.029)$. It is important to note that the symptoms of hypoglycemia resulting from the insulin therapy were not observed in any of the patients. Similar results were supported by Greenway et al. indicating that topical insulin is an accelerator of wound healing in humans. ${ }^{73}$ Scimeca et al. using NPWTi with insulin in a case report confirmed the efficacy for the treatment of chronic wounds due to emergency amputation at the midfoot level. ${ }^{34}$

\section{Clinical indications}

The review of recent publications concerning NPWTi are summarized in Table 2.

In 1988, W. Fleischmann who is considered as a pioneer in NPWT instillation and negative pressure therapy, published 
Table II

TABLE 2. RECENT STUDIES CONCERNING NEGATIVE PRESSURE WOUND THERAPY WITH INSTILLATION

\begin{tabular}{|c|c|c|c|c|c|c|c|c|}
\hline Author and year & Type of study & $\begin{array}{l}\text { Number } \\
\text { of } \\
\text { NPWTi } \\
\text { patients }\end{array}$ & Type of instilled fluid & $\begin{array}{l}\text { Instill } \\
\text { time } \\
(\mathrm{sec})\end{array}$ & $\begin{array}{l}\text { Dwell } \\
\text { time }\end{array}$ & $\begin{array}{l}\text { Instillation cycle } \\
\text { (hour) }\end{array}$ & $\begin{array}{l}\text { Negative } \\
\text { pressure }\end{array}$ & $\begin{array}{l}\text { Days } \\
\text { NPWTi }\end{array}$ \\
\hline & & & & & & & $(\mathrm{mmHg})$ & mean (range) \\
\hline \multirow[t]{2}{*}{$\begin{array}{l}\text { Fleischmann } \\
\text { al., } 199840\end{array}$} & Case series & 27 & $\begin{array}{l}\text { Nebacetin (neomycin and } \\
\text { bacitracin) plus polyhex- } \\
\text { anidine }\end{array}$ & NA & $30 \mathrm{~min}$ & NA & $\begin{array}{l}\text { Od }-50 \\
\text { do }\end{array}$ & $33,5(30-37)$ \\
\hline & & & & & & & -600 & \\
\hline 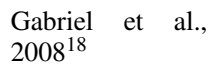 & Retrospective & 15 & Silver nitrate & 30 & $1 \mathrm{sec}$ & Every 2 hour & -125 & $9,8(5-20)$ \\
\hline Wolvos, 200441 & Case series & 5 & $\begin{array}{l}1 \text { or } 2 \% \text { Lidocaine }+ \text { an- } \\
\text { tibiotic } 1\end{array}$ & $15-60$ & $5 \mathrm{~min}$ & Every 3 hour & -125 & $15(5-24)$ \\
\hline $\begin{array}{lc}\text { Bernstein } & \text { BH } \\
\text { and Tam H, } & \text { 200574 }\end{array}$ & Case series & 5 & $\begin{array}{l}\text { Polymyxin }(500.000 \mathrm{IU}) \\
\text { plus Bacitracin }(50.000 \\
\mathrm{IU}) \text { in } 2 \mathrm{~L} \text { of saline }\end{array}$ & 90 & $5 \mathrm{~min}$ & Every 6 hour & -125 & NA \\
\hline $\begin{array}{l}\text { Brinkert et al., } \\
201328\end{array}$ & Prospective & 131 & Saline & 20 & $10 \mathrm{~min}$ & $\begin{array}{ll}\begin{array}{l}\text { Every } 6 \\
\text { (range: }\end{array} & \text { hour } \\
4-12 \text { hour) } & \end{array}$ & -125 & 12,19 \\
\hline Kim et al., 2015 & $\begin{array}{l}\text { Prospective, } \\
\text { randomized }\end{array}$ & 100 & $\begin{array}{l}\text { Saline versus } 0.1 \% \text { Poly- } \\
\text { hexanide }+0,1 \% \text { Betadine }\end{array}$ & NA & $20 \mathrm{~min}$ & Every 2 hour & NA & NA \\
\hline \multicolumn{9}{|l|}{43} \\
\hline $\begin{array}{l}\text { Gabriel et al., } \\
2014^{75}\end{array}$ & Retrospective & 48 & Saline or Prontosan $\mathbb{R}$ & NA & $1-60 \mathrm{sec}$ & Every 2 hour & -125 & NA \\
\hline $\operatorname{Kim}_{2014 \sqrt{38}}$ et al., & Retrospective & 68 & 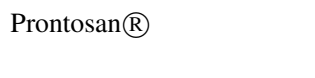 & NA & $\begin{array}{l}6 \text { or } 20 \\
\min \end{array}$ & $\begin{array}{l}\text { Every } 2 \text { or } 3,5 \\
\text { hour }\end{array}$ & -125 & NA \\
\hline $\begin{array}{l}\text { Goss et al., } \\
2014^{36}\end{array}$ & Prospective & 7 & $\begin{array}{l}0,125 \% \text { Dakin's solution } \\
\text { ("quarter strength") }\end{array}$ & NA & $10 \mathrm{~min}$ & Every 1 hour & -125 & 7 \\
\hline $\begin{array}{l}\text { Fluieraru et al., } \\
201344\end{array}$ & Retrospective & 24 & Saline & 30 & $10 \mathrm{~min}$ & Every 4 hour & -125 & $10,1(6-15)$ \\
\hline Wolvos, 201337 & Case series & 6 & $\begin{array}{l}\text { Microcyn or Dakin's solu- } \\
\text { tion ("quarter strength") }\end{array}$ & NA & $\begin{array}{l}5 \text { or } 10 \\
\min \end{array}$ & Every 2 or 4 hour & $\begin{array}{l}\text { From } \\
-100 \text { to } \\
-125\end{array}$ & Jul 54 \\
\hline $\begin{array}{l}\text { Lehner } \\
2011^{39}\end{array}$ et al. & $\begin{array}{l}\text { Prospective, } \\
\text { multicenter }\end{array}$ & 32 & 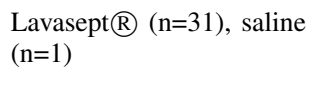 & $<60$ & $\begin{array}{l}19 \min \\
(5-30)\end{array}$ & $\begin{array}{l}\text { From } 5 \text { to } 40 \text { cy- } \\
\text { cles/day }\end{array}$ & $\begin{array}{l}\text { From } \\
-125 \text { to } \\
-200\end{array}$ & $16,3(9-46)$ \\
\hline Koster, 200ð61 & Case series & 10 & Lavasept $(\mathbb{2}$ & Okt 20 & $\begin{array}{l}10-15 \\
\min \end{array}$ & NA & NA & 03. Sep \\
\hline $\begin{array}{l}\text { Leffler } \\
200076\end{array}$ et al., & Case series & 6 & Lavasept $\AA$ & 20 & $20 \mathrm{~min}$ & Every 4 hour & -125 & NA \\
\hline
\end{tabular}

an initial study concerning the influence of instilled fluid on the wound treatment ${ }^{40}$ Using NPWTi with antiseptic or antibiotic solutions in 27 patients with acute and chronic infections of bone and soft tissue as well as chronic osteomyelitis, they confirmed the efficiency of NPWTi in 26 patients with one recurrence of infection during 3-14 months of follow-up. Gabriel et al. published a retrospective study comparing patients treated with NPWTi and standard moist wound care 18 The majority of patients were treated with NPWTi due to pressure ulcers, extremity trauma (including bone exposure) and abdominal surgical wounds. In the NPWTi group of treatment the time of required treatment, wound closure, resolution of wound infection and hospital stay were significantly shorter in comparison to the standard method of treatment $(p<0.001)$. Wolvos in his initial report of clinical practice with NPWTi described a routine use of combined Lidocaine and antibiotic solution for the purpose of chronic and complex wound treatment. ${ }^{41}$ Surprisingly, all patients reported a reduction in pain following NPWT instillation with 1-2\% Lidocaine as a topical anesthetic. Wolvos also observed that an appropriate, targeted antibiotic (based on the microbiological results) decreased the bacterial burden in the wound. Bernstein and Tam described a case series of patients with post-surgical diabetic foot wounds treated with NPWTi ${ }^{74}$ Based on their initial experience, the application of topical antibiotics positively influences the progress of wound healing in chronic and complex wounds after surgical management in DM patients. In authors' opinion, NPWTi positively affects the wound fluid viscosity, decreasing inflammatory agents and cellular debris and it also reduces bacterial burden. Brinkert et al. in a prospective study compared the efficiency of NPWTi and standard NPWT in a group of 131 patients treated in three referral orthopedic or surgical centers in France. ${ }^{28}$ The most common clinical indication for both NPWTi and standard NPWT was an open fracture $(n=46)$, pressure ulcer $(n=27)$ and non-healing postoperative dehiscence $(n=25)$. Wound closure 
was possible to be achieved in $98 \%$ of patients treated with NPWTi with the mean duration of the therapy 12,19 days. In the recent prospective randomized study, Kim et al. analyzed the effect of NPWTi on wound healing using two different solutions: normal saline versus antiseptic solution $(0.1 \%$ polyhexanide plus $0,1 \%$ betaine) ${ }^{43}$ In the majority, chronic or complex wound was located within the lower extremity in both analyzed groups of treatment. There was no statistical difference between the compared groups of treatment for the number of surgeries, the length of hospital stay, wounds closed/ covered ratio and wounds ratio that remained closed within 30 days of follow up. The only significance was the time to final surgical procedure which was favorable in NPWTi with saline solution group $(\mathrm{p}=0,038)$. Based on this study, normal saline and antiseptic solution $(0.1 \%$ polyhexanide plus $0,1 \%$ betaine) demonstrate a similar efficacy. Gabriel et al. compared the standard NPWT and NPWTi with saline or polyhexanide in patients with extremity or trunk wounds 75 A total of 48 patients treated with NPWTi showed a statistical significance in comparison to the standard NPWT for the time of hospital stay (8,1vs 27,4 days), duration of the therapy $(4,1$ vs 20,9 days), time of wound closure (4,1 vs 20,9 days) and mean operating room debridement $(2,0$ vs 4,4$)$. Goss et al. in a prospective pilot study evaluated the efficacy of the reduction of a wound bacterial bioburden comparing the standard NPWT and NPWTi ${ }^{36}$ Dakin's solution was used as an instilled bactericidal agent. Chronic venous stasis and diabetic foot ulcer were the most common underlying wound pathologies in both treatment groups with the mean time of wound duration 30 months in the standard NPWT group and 23 months in NPWTi group. At the time of end point ( 7 th day of the therapy), there was no statistically significant difference between these two groups in reduction of bacterial bioburden (CFU/ gram of tissue culture; $\mathrm{p}=0,43$ ). However, the mean absolute reduction of bacterial bioburden was statistically significant in NPWTi group versus standard NPWT $(\mathrm{p}=0,016)$. Fluieraru et al. used NPWTi as the primary method of treatment for extensive undermining deep wounds $(n=12)$ as well as in patients who failed the standard NPWT $(n=12)$. 44 Isotonic saline was used as an instilled fluid with a 10-minute dwell time and 30 seconds of instillation. There was no complication associated with NPWTi. In 23 patients wound closure was achieved using flaps or skin grafts following preconditioning of the wound bed with the use of NPWTi. In all patients, good results of tissue granulation and filling of the wound cavities were observed.

Recently, Wolvos published a small case series of patients treated with NPWTi in contaminated, chronic abdominal wounds $(n=3)$ or infected wounds within the lower extremity $(n=2)$ and chest wall $(n=1) \cdot \frac{37}{}$ Wound healing and closure were achieved in all patients using skin graft or surgical closure (primary, secondary or delayed primary). There was no difference in quality and the amount of tissue granulation in patients treated with NPWTi $(n=6)$ and standard NPWT $(n=1)$, even though both groups were small and inconsistent regarding the types of the underlying pathologies of the wound and the degree of the contamination, which is a limitation of the study. In 2011 Lehner et al. published a multi-center prospective observational study concerning the utility of NPWTi in patients following hip and knee replacements with surgical site infection associated with orthopaedic implants. ${ }^{39}$ Clinical indication for introduction of NPWTi included infected hip implant $(n=20)$, infected knee implant $(n=10)$ and 2 patients with infected osteosynthesis material. Routinely, polyhexanide was used as an instilled fluid in all but one patient in whom saline was used. Twenty-two patients had an acute infection ( $<8$ weeks after orthopedic implant placement), whereas ten patients had a chronic infection (between 8 and 36 weeks postoperatively). After NPWTi course, an eradication of the wound infection was confirmed in 24 patients (75\%), whereas in 6 patients the recurrence of the wound infection was revealed $(18,8 \%)$ and in 2 patients ongoing wound infection was reported. Koster presented ten patients with an implantassociated infection following a knee implant placement.61 After a required wound debridement, NPWTi was initialized using Lavasept $\AA$. During the observational period of 13-34 months after a completed NPWTi therapy, only in one patient there was a case of a reinfection. Similar results were achieved

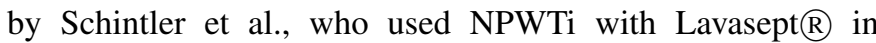
patients with soft tissue infections and necrotizing fasciitis $\frac{77}{7}$ Additionally, in eight patients bone exposure or septic arthritis were observed. The time of administration of NPWTi ranged from 4 to 18 days. In all patients wound closure was achieved using skin graft, flaps or secondary closure. Leffler et al. described a small case series of 6 patients with osteomyelitis within the lower extremity $(n=5)$ or the upper extremity $(n=1)$ treated with NPWTi ${ }^{76}$ Lavasept $($ ) was used as an instilled fluid with the following settings: 20 seconds of instillation with 20-minute dwell time followed by NPWT at $-125 \mathrm{mmHg}$. After the NPWTi therapy, sterile bacterial cultures from the site of an infection were confirmed in all patients. There was no recurrence of a wound infection following a flap reconstruction. Also, they did not observe a flap loss due to the impairment of wound healing.

\section{Contraindications AND WARnings}

Similarly to the standard NPWT, the list of indications for NPWT with instillation has been recently increased. There has been a tremendous progress in in the field of NPWT as well as NPWT with instillation leading to the fact that this therapy is currently used in many clinical scenarios.

However, there are some clinical situations when more attention should be taken. Some solutions should also be avoided as an instillation. Contraindications for NPWTi are exactly the same as for standard NPWT and include: exposed blood vessels or nerves, exposed bowels (or qualified for abdominal NPWT) or anastomotic sites. Solutions containing octenidine, hydrogen peroxide and other alcohol-based products are contraindicated in NPWT with instillation because of their interactions and potential destructive effect on foam

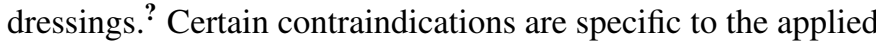
solution. For example, neomycin may be absorbed locally and an increased serum concentration may result in nephrotoxic and ototoxic reactions. ${ }^{78}$ Anaphylaxis caused by the local administration of Bacitracin or Polymyxin B or when used as an irrigation was also reported ${ }^{791}$ Although some authors 
reported shock, coma or even death related to povidone iodine solution and hydrogen peroxide utility in surgical debridement, generally both local antiseptics seem to be safe and generally recommended for the purpose of wound cleansing 82.83

Fluid instillation should not be delivered directly to the abdominal or thoracic cavities. ${ }^{84}$ Firstly, a potential retention within the human cavity may decrease the body temperature. Secondly, instilled fluid may be retained within the body cavities and may not be properly suctioned. Thus, the cases with a present bacterial inflammation may lead to intra-abdominal/ intrathoracic abscesses formation, despite the proper maintenance and application of negative pressure. However, D'Hondt et al. recently described a case report of NPWTi use in a patient treated with open abdomen management following a pancreatic surgery ${ }^{[85}$ Due to a failure of previous therapy (included abdominal NPWT), NPWT with gentamicin and metronidazole (based on antibiogram results) was implemented. Instillation time was set for 20 seconds with 10 minutes of dwell time and a negative pressure of $-125 \mathrm{mmHg}$. During the 12-day no local or systemic side effects of NPWTi were observed and the eradication of $\mathrm{B}$. fragilis, $\mathrm{P}$. aeruginosa and Lactobacillus was confirmed based on abdominal cultures. It is important to note that described patient developed frozen abdomen. Thus, possibly the retention of instilled fluid is minimized by the granulated tissue preventing it from pooling the solution directly through the entire abdominal cavity. Based on our experience, we agree with the authors that NPWTi may serve as an important alternative when the standard open abdomen therapy fails. However, further research and clinical trials are required to evaluate the safety and efficiency of NPWTi in open abdomen. Because of the above mentioned reasons, NPWT with instillation should be avoided in clinical situations with unexplored wound or a potential tunnel drained into body cavities. NPWTi should not be placed over skin flaps or grafts with a potential risk of failure and problems with adapting and healing of the skin flaps or grafts.

\section{CONCLUSIONS}

Based on current knowledge supported by clinical trials, NPWTi is found as an important alternative to standard NPWT in many clinical scenarios. Moreover, in some publications the superiority of NPWTi over standard NPWT was highlighted.

Further studies regarding both basic science as well as clinical trials are needed to establish the firm conclusions concerning the efficiency of NPWTi.

From practical point of view, in authors' opinion it is important to share experience and collect data from varying institutions in different clinical indications to create firm conclusions and form guidelines for NPWTi.

\section{REFERENCES}

[1] W. Fleischmann, W. Strecker, M. Bombelli, and L. Kinzl, "[vacuum sealing as treatment of soft tissue damage in open fractures]," Unfallchirurg, vol. 96, p. 488-492, 1993.

[2] W. Fleischmann, M. Russ, and C. Marquardt, "Defektwundenverschluß durch kombination von vakuumversiegelung mit instrumenteller hautdehnung," Der Unfallchirurg, vol. 99, no. 12, pp. 970-974, dec 1996. [Online]. Available: http://dx.doi.org/10.1007/s001130050082
[3] L. C. Argenta and M. J. Morykwas, "Vacuum-assisted closure: A new method for wound control and treatment," Annals of Plastic Surgery, vol. 38, no. 6, pp. 563-577, jun 1997. [Online]. Available: http://dx.doi.org/10.1097/00000637-199706000-00002

[4] M. Baharestani, I. Amjad, K. Bookout, T. Fleck, A. Gabriel, D. Kaufman, S. S. McCord, D. C. Moores, O. O. Olutoye, J. D. Salazar, D. H. Song, S. Teich, and S. Gupta, "V.a.c. (R therapy in the management of paediatric wounds: clinical review and experience," International Wound Journal, vol. 6, pp. 1-26, aug 2009. [Online]. Available: http://dx.doi.org/10.1111/j.1742-481X.2009.00607.x

[5] J. Beitz and L. van Rijswijk, "Developing evidence-based algorithms for negative pressure wound therapy in adults with acute and chronic wounds: literature and expert-based face validation results," Ostomy Wound Manage., vol. 58, no. 4, pp. 50-69, 2012.

[6] L. Krokowicz, M. Borejsza-Wysocki, J. Mackiewicz, A. Iqbal, and M. Drews, "10 years of negative pressure wound therapy [npwt]: evolution of indications for its use," Negative Pres. Wound Ther, vol. 1, pp. 27-32, 2014.

[7] P. J. Kim, C. E. Attinger, J. S. Steinberg, K. K. Evans, B. Lehner, C. Willy, L. Lavery, T. Wolvos, D. Orgill, W. Ennis, J. Lantis, A. Gabriel, and G. Schultz, "Negative pressure wound therapy with instillation," Plastic and Reconstructive Surgery, p. 1, sep 2013. [Online]. Available: http://dx.doi.org/10.1097/prs.0b013e3182a80586

[8] D. P. Orgill and L. R. Bayer, "Update on negative-pressure wound therapy," Plastic and Reconstructive Surgery, vol. 127, pp. 105S115S, jan 2011. [Online]. Available: http://dx.doi.org/10.1097/PRS. 0b013e318200a427

[9] A. Gabriel, J. Shores, B. Bernstein, J. de Leon, R. Kamepalli, T. Wolvos, M. M. Baharestani, and S. Gupta, "A clinical review of

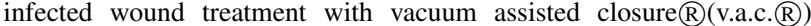
therapy: Experience and case series," International Wound Journal, vol. 6, pp. 1-25, oct 2009. [Online]. Available: http://dx.doi.org/10. 1111/j.1742-481X.2009.00628.x

[10] S. Ichioka, H. Watanabe, N. Sekiya, M. Shibata, and T. Nakatsuka, "A technique to visualize wound bed microcirculation and the acute effect of negative pressure," Wound Repair and Regeneration, vol. 16, no. 3, pp. 460-465, may 2008. [Online]. Available: http://dx.doi.org/10.1111/j.1524-475X.2008.00390.x

[11] S. S. Scherer, G. Pietramaggiori, J. C. Mathews, M. J. Prsa, S. Huang, and D. P. Orgill, "The mechanism of action of the vacuum-assisted closure device," Plastic and Reconstructive Surgery, vol. 122, no. 3, pp. 786-797, sep 2008. [Online]. Available: http://dx.doi.org/10.1097/PRS.0b013e31818237ac

[12] A. K. McNulty, M. Schmidt, T. Feeley, and K. Kieswetter, "Effects of negative pressure wound therapy on fibroblast viability, chemotactic signaling, and proliferation in a provisional wound (fibrin) matrix," Wound Repair and Regeneration, vol. 15, no. 6, pp. 838-846, nov 2007. [Online]. Available: http://dx.doi.org/10.1111/j.1524-475X.2007. 00287.x

[13] V. Saxena, C.-W. Hwang, S. Huang, Q. Eichbaum, D. Ingber, and D. P. Orgill, "Vacuum-assisted closure: Microdeformations of wounds and cell proliferation," Plastic and Reconstructive Surgery, pp. 1086-1096, oct 2004. [Online]. Available: http://dx.doi.org/10.1097/01. PRS.0000135330.51408.97

[14] N. Wang, J. Butler, and D. Ingber, "Mechanotransduction across the cell surface and through the cytoskeleton," Science, vol. 260, no. 5111, pp. 1124-1127, may 1993. [Online]. Available: http://dx.doi.org/10.1126/science.7684161

[15] D. E. Ingber, "TENSEGRITY: THE ARCHITECTURAL BASIS OF CELLULAR MECHANOTRANSDUCTION," Annual Review of Physiology, vol. 59, no. 1, pp. 575-599, oct 1997. [Online]. Available: http://dx.doi.org/10.1146/annurev.physiol.59.1.575

[16] K. Buttenschoen, W. Fleischmann, U. Haupt, L. Kinzl, and D. C. Buttenschoen, "The influence of vacuum-assisted closure on inflammatory tissue reactions in the postoperative course of ankle fractures," Foot and Ankle Surgery, vol. 7, no. 3, pp. 165-173, jan 2001. [Online]. Available: http://dx.doi.org/10.1046/j.1460-9584.2001.00258.x

[17] J. Wimpenny, W. Manz, and U. Szewzyk, "Heterogeneity in biofilms: Table 1," FEMS Microbiology Reviews, vol. 24, no. 5, pp. 661-671, dec 2000. [Online]. Available: http://dx.doi.org/10.1111/j.1574-6976. 2000.tb00565.x

[18] A. Gabriel, J. Shores, C. Heinrich, W. Baqai, S. Kalina, N. Sogioka and S. Gupta, "Negative pressure wound therapy with instillation: a pilot study describing a new method for treating infected wounds,' Int Wound Journal, vol. 5, no. 3, pp. 399-413, jun 2008. [Online]. Available: http://dx.doi.org/10.1111/j.1742-481X.2007.00423.x 
[19] S. L. Percival, K. E. Hill, D. W. Williams, S. J. Hooper, D. W. Thomas, and J. W. Costerton, "A review of the scientific evidence for biofilms in wounds," Wound Repair and Regeneration, vol. 20, no. 5, pp. 647-657, sep 2012. [Online]. Available: http://dx.doi.org/10.1111/j.1524-475X.2012.00836.x

[20] E. A. Grice and J. A. Segre, "Interaction of the microbiome with the innate immune response in chronic wounds," in Advances in Experimental Medicine and Biology. Springer Science + Business Media, sep 2011, pp. 55-68. [Online]. Available: http://dx.doi.org/10. 1007/978-1-4614-0106-3_4

[21] G. A. James, E. Swogger, R. Wolcott, E. deLancey Pulcini, P. Secor, J. Sestrich, J. W. Costerton, and P. S. Stewart, "Biofilms in chronic wounds," Wound Repair and Regeneration, vol. 16, no. 1, pp. 37-44, jan 2008. [Online]. Available: http://dx.doi.org/10.1111/j.1524-475X. 2007.00321.x

[22] P. L. Phillips, Q. Yang, and G. S. Schultz, "The effect of negative pressure wound therapy with periodic instillation using antimicrobial solutions on pseudomonas aeruginosa biofilm on porcine skin explants,' International Wound Journal, vol. 10, no. s1, pp. 48-55, nov 2013. [Online]. Available: http://dx.doi.org/10.1111/iwj.12180

[23] D. Allen, L. A. LaBarbera, I. L. Bondre, M. C. Lessing, A. M. Rycerz, D. V. Kilpadi, B. A. Collins, J. Perkins, and A. K. McNulty, "Comparison of tissue damage, cleansing and cross-contamination potential during wound cleansing via two methods: lavage and negative pressure wound therapy with instillation," International Wound Journal, vol. 11, no. 2, pp. 198-209, aug 2012. [Online]. Available: http://dx.doi.org/10.1111/j.1742-481X.2012.01073.x

[24] S. L. Percival, C. Vuotto, G. Donelli, and B. A. Lipsky, "Biofilms and wounds: An identification algorithm and potential treatment options,' Advances in Wound Care, vol. 4, no. 7, pp. 389-397, jul 2015. [Online]. Available: http://dx.doi.org/10.1089/wound.2014.0574

[25] R. Wolcott, K. Rumbaugh, G. James, G. Schultz, P. Phillips, Q. Yang, C. Watters, P. Stewart, and S. Dowd, "Biofilm maturity studies indicate sharp debridement opens a time-dependent therapeutic window,' Journal of Wound Care, vol. 19, no. 8, pp. 320-328, aug 2010 [Online]. Available: http://dx.doi.org/10.12968/jowc.2010.19.8.77709

[26] C. Attinger and R. Wolcott, "Clinically addressing biofilm in chronic wounds," Advances in Wound Care, vol. 1, no. 3, pp. 127-132, jun 2012. [Online]. Available: http://dx.doi.org/10.1089/wound.2011.0333

[27] B. Leung, L. LaBarbera, C. Carroll, D. Allen, and A. McNulty, "The effects of normal saline instillation in conjunction with negative pressure wound therapy on wound healing in a porcine model.'

[28] D. Brinkert, M. Ali, M. Naud, N. Maire, C. Trial, and L. Téot, "Negative pressure wound therapy with saline instillation: 131 patien case series," International Wound Journal, vol. 10, no. s1, pp. 56-60, nov 2013. [Online]. Available: http://dx.doi.org/10.1111/iwj.12176

[29] M. Lessing, R. James, and S. Ingram, "Comparison of the effects of different negative pressure wound therapy modes - continuous, noncontinuous, and with instillation - on porcine excisional wounds," Eplasty, vol. 13, p. e51, 2013

[30] C. Lessing, P. Slack, K. Hong, D. Kilpadi, and A. McNulty, "Negative pressure wound therapy with controlled saline instillation (npwti): Dressing properties and granulation response in vivo,' Wounds, vol. 23, no. 10 , pp. 309-19, 2011.

[31] G. S. Schultz, R. G. Sibbald, V. Falanga, E. A. Ayello, C. Dowsett K. Harding, M. Romanelli, M. C. Stacey, L. Teot, and W. Vanscheidt, "Wound bed preparation: a systematic approach to wound management," Wound Repair and Regeneration, vol. 11, no. s1, pp. S1-S28, mar 2003 [Online]. Available: http://dx.doi.org/10.1046/j.1524-475X.11.s2.1.x

[32] R. Wilkes, Y. Zhao, K. Cunningham, K. Kieswetter, and B. Haridas, " $3 \mathrm{~d}$ strain measurement in soft tissue: Demonstration of a novel inverse finite element model algorithm on MicroCT images of a tissue phantom exposed to negative pressure wound therapy," Journal of the Mechanical Behavior of Biomedical Materials, vol. 2, no. 3, pp. 272-287, jul 2009. [Online]. Available: http://dx.doi.org/10.1016/j.jmbbm.2008.10.006

[33] A. M. Rycerz, P. Slack, and A. K. McNulty, "Distribution assessment comparing continuous and periodic wound instillation in conjunction with negative pressure wound therapy using an agar-based model," International Wound Journal, vol. 10, no. 2, pp. 214-220, apr 2012 [Online]. Available: http://dx.doi.org/10.1111/j.1742-481X.2012.00968. $\mathrm{X}$

[34] C. L. Scimeca, M. Bharara, T. K. Fisher, N. Giovinco, and D. G. Armstrong, "Novel use of doxycycline in continuous-instillation negative pressure wound therapy as "wound chemotherapy"," Foo \& Ankle Specialist, vol. 3, no. 4, pp. 190-193, jun 2010. [Online]. Available: http://dx.doi.org/10.1177/1938640010371121
[35] M. J. Morykwas, L. C. Argenta, E. I. Shelton-Brown, and W. McGuirt, "Vacuum-assisted closure: A new method for wound control and treatment," Annals of Plastic Surgery, vol. 38, no. 6, pp. 553-562, jun 1997. [Online]. Available: http://dx.doi.org/10.1097/ 00000637-199706000-00001

[36] S. Goss, J. Schwartz, F. Facchin, E. Avdagic, C. Gendics, and J. Lantis, "Negative pressure wound therapy with instillation (NPWTi) better reduces post-debridement bioburden in chronically infected lower extremity wounds than NPWT alone," Journal of the American College of Clinical Wound Specialists, vol. 4, no. 4, pp. 74-80, dec 2012. [Online]. Available: http://dx.doi.org/10.1016/j.jccw.2014.02.001

[37] T. Wolvos, "The use of negative pressure wound therapy with an automated, volumetric fluid administration: an advancement in wound care," Wounds, vol. 25, p. 75-83, 2013.

[38] J. Matiasek, G. Djedovic, M. Mattesich, E. Morandi, R. Pauzenberger, R. Pikula, R. Verstappen, G. Pierer, R. Koller, and U. Rieger, "The combined use of NPWT and instillation using an octenidine based wound rinsing solution: a case study," Journal of Wound Care, vol. 23, no. 11, pp. 590-596, nov 2014. [Online]. Available: http://dx.doi.org/10.12968/jowc.2014.23.11.590

[39] "Lehner, b and weiss, s and suda, aj and witte, d," Infection, vol. 37, p 13-17, 2009

[40] W. Fleischmann, M. Russ, A. Westhauser, and M. Stampehl, "Vacuumsealing-technique used as drug release system for topical treatment of wound infections," Der Unfallchirurg, vol. 101, no. 8, pp. 649-654, aug 1998. [Online]. Available: http://dx.doi.org/10.1007/s001130050318

[41] T. Wolvos, "Wound instillation-the next step in negative pressure wound therapy. lessons learned from initial experiences," Ostomy Wound Manage, no. 11, pp. 56-66, 2004

[42] F.-Y. Chang, M.-C. Chang, S.-T. Wang, W.-K. Yu, C.-L. Liu, and T.-H. Chen, "Can povidone-iodine solution be used safely in a spinal surgery?" European Spine Journal, vol. 15, no. 6, pp. 1005-1014, aug 2005. [Online]. Available: http://dx.doi.org/10.1007/s00586-005-0975-6

[43] P. J. Kim, C. E. Attinger, N. Oliver, C. Garwood, K. K. Evans, J. S. Steinberg, and L. A. Lavery, "Comparison of outcomes for normal saline and an antiseptic solution for negative-pressure wound therapy with instillation," Plastic and Reconstructive Surgery, vol. 136, no. 5, pp. 657e-664e, 2015. [Online]. Available: http: //dx.doi.org/10.1097/PRS.0000000000001709

[44] S. Fluieraru, F. Bkara, M. Naud, C. Herlin, C. Faure, C. Trial, and L. Téot, "Sterile-water negative pressure instillation therapy for complex wounds and NPWT failures," Journal of Wound Care, vol. 22, no. 6, pp. 293-299, jun 2013. [Online]. Available: http://dx.doi.org/10.12968/jowc.2013.22.6.293

[45] K. Davis, J. Bills, J. Barker, P. Kim, and L. Lavery, "Simultaneous irrigation and negative pressure wound therapy enhances wound healing and reduces wound bioburden in a porcine model," Wound Repair and Regeneration, vol. 21, no. 6, pp. 869-875, oct 2013. [Online]. Available: http://dx.doi.org/10.1111/wrr.12104

[46] M. King, "Our historical roots," Journal of Wound, Ostomy and Continence Nursing, vol. 35, no. 3, pp. 289-292, may 2008. [Online]. Available: http://dx.doi.org/10.1097/01.WON.0000319127.98983.2c

[47] M. McCullough and G. W. Carlson, "Dakin's solution," Annals of Plastic Surgery, vol. 73, no. 3, pp. 254-256, sep 2014. [Online]. Available: http://dx.doi.org/10.1097/SAP.0b013e3182a634f7

[48] D. Doughty, "A rational approach to the use of topical antiseptics," Journal of Wound, Ostomy and Continence Nursing, vol. 21, no. 6, pp. 224-231, nov 1994. [Online]. Available: http://dx.doi.org/10.1097/ 00152192-199411000-00008

[49] A. Agostinho, A. Hartman, C. Lipp, A. Parker, P. Stewart, and G. James, "An in vitro model for the growth and analysis of chronic wound MRSA biofilms," Journal of Applied Microbiology, vol. 111, no. 5, pp. 1275-1282, sep 2011. [Online]. Available: http://dx.doi.org/10.1111/j.1365-2672.2011.05138.x

[50] M. L. COOPER, J. A. LAXER, and J. F. HANSBROUGH, "The cytotoxic effects of commonly used topical antimicrobial agents on human fibroblasts and keratinocytes," The Journal of Trauma: Injury, Infection, and Critical Care, vol. 31, no. 6, pp. 775-784, jun 1991. [Online]. Available: http://dx.doi.org/10.1097/ 00005373-199106000-00007

[51] J. P. Heggers, J. A. Sazy, B. D. Stenberg, L. L. Strock, R. L. McCauley, D. N. Herndon, and M. C. Robson, "Bactericidal and wound-healing properties of sodium hypochlorite solutions: The 1991 lindberg award," Journal of Burn Care \& Rehabilitation, vol. 12, no. 5, pp. 420-424, sep 1991. [Online]. Available: http://dx.doi.org/10.1097/00004630-199109000-00005 
[52] R. A. Kozol, "Effects of sodium hypochlorite (dakin's solution) on cells of the wound module," Arch Surg, vol. 123, no. 4, p. 420, apr 1988. [Online]. Available: http://dx.doi.org/10.1001/archsurg.1988. 01400280026004

[53] W. Lineaweaver, "Topical antimicrobial toxicity," Arch Surg, vol. 120, no. 3, p. 267, mar 1985. [Online]. Available: http://dx.doi.org/10.1001/ archsurg.1985.01390270007001

[54] K. Sauer, E. Thatcher, R. Northey, and A. A. Gutierrez, "Neutral super-oxidised solutions are effective in killing p. aeruginosa biofilms,' Biofouling, vol. 25, no. 1, pp. 45-54, jan 2009. [Online]. Available: http://dx.doi.org/10.1080/08927010802441412

55] C. Landa-Solis, D. González-Espinosa, B. Guzmán-Soriano, M. Snyder, G. Reyes-Terán, K. Torres, and A. Gutierrez, "Microcyntm: a novel super-oxidized water with neutral $\mathrm{pH}$ and disinfectant activity," Journal of Hospital Infection, vol. 61, no. 4, pp. 291-299, dec 2005. [Online]. Available: http://dx.doi.org/10.1016/j.jhin.2005.04.021

[56] C. Goretti, S. Mazzurco, L. A. Nobili, S. Macchiarini, A. Tedeschi, F. Palumbo, A. Scatena, L. Rizzo, and A. Piaggesi, "Clinical outcomes of wide postsurgical lesions in the infected diabetic foot managed with 2 different local treatment regimes compared using a quasi-experimental study design: A preliminary communication," The International Journal of Lower Extremity Wounds, vol. 6, no. 1, pp. 22-27, mar 2007. [Online]. Available: http://dx.doi.org/10.1177/1534734606298543

[57] A. Landsman, P. A. Blume, D. A. Jordan, D. Vayser, and A. Gutierrez, "An open-label, three-arm pilot study of the safety and efficacy of topical microcyn rx wound care versus oral levofloxacin versus combined therapy for mild diabetic foot infections," Journal of the American Podiatric Medical Association, vol. 101, no. 6, pp. 484-496, nov 2011. [Online]. Available: http://dx.doi.org/10.7547/1010484

[58] K. Minnich, R. Stolarick, R. Wilkins, G. Chilson, S. Pritt, and M. Unverdorben, "The effect of a wound care solution containing polyhexanide and betaine on bacterial counts: Results of an in vitro study," Ostomy Wound Manage, vol. 58, p. 32-36, 2012

[59] M. Romanelli, V. Dini, S. Barbanera, and M. Bertone, "Evaluation of the efficacy and tolerability of a solution containing propyl betaine and polihexanide for wound irrigation," Skin Pharmaco Physiol, vol. 23, no. 1, pp. 41-44, 2010. [Online]. Available: http://dx.doi.org/10.1159/000318266

[60] R. G. Sibbald, P. Coutts, and K. Y. Woo, "Reduction of bacterial burden and pain in chronic wounds using a new polyhexamethylene biguanide antimicrobial foam dressing-clinical trial results," Advances in Skin \& Wound Care, vol. 24, no. 2, pp. 78-84, feb 2011. [Online] Available: http://dx.doi.org/10.1097/01.ASW.0000394027.82702.16

[61] G. Koster, "Management of early periprosthetic infections in the knee using the vacuum-instillation therapy," Infection, vol. 37, p. 18-20, 2009.

[62] H. Q. Yin, R. Langford, and R. E. Burrell, "Comparative evaluation of the antimicrobial activity of ACTICOAT antimicrobial barrier dressing," Journal of Burn Care \& Rehabilitation, vol. 20, no. 3, pp. 195-200, may 1999. [Online]. Available: http://dx.doi.org/10.1097/ 00004630-199905000-00006

[63] J. B. Wright, K. Lam, A. G. Buret, M. E. Olson, and R. E. Burrell, "Early healing events in a porcine model of contaminated wounds: effects of nanocrystalline silver on matrix metalloproteinases, cell apoptosis, and healing," Wound Repair and Regeneration, vol. 10, no. 3, pp. 141-151, may 2002. [Online]. Available: http://dx.doi.org/10.1046/j.1524-475X.2002.10308.x

[64] H. Schreier, G. Erdos, K. Reimer, B. K\&oumlnig, W. K\&oumlnig, and W. Fleischer, "Molecular effects of povidone-iodine on relevan microorganisms: An electron-microscopic and biochemical study," Dermatology, vol. 195, no. 2, pp. 111-116, 1997. [Online]. Available: http://dx.doi.org/10.1159/000246043

[65] T. Kunisada, K. Yamada, S. Oda, and O. Hara, "Investigation on the efficacy of povidone-iodine against antiseptic-resistant species,' Dermatology, vol. 195, no. 2, pp. 14-18, 1997. [Online]. Available: http://dx.doi.org/10.1159/000246025

[66] K. K. Kaysinger, N. C. Nicholson, W. K. Ramp, and J. F. Kellam, "Toxic effects of wound irrigation solutions on cultured tibiae and osteoblasts," Journal of Orthopaedic Trauma, vol. 9, no. 4, pp. 303-311, 1995. [Online]. Available: http://dx.doi.org/10.1097/ 00005131-199509040-00006

[67] I. Fumal, C. Braham, P. Paquet, C. Pi\&eacuterard-Franchimont, and G. Pi\&eacuterard, "The beneficial toxicity paradox of antimicrobials in leg ulcer healing impaired by a polymicrobial flora: A proof-of-concept study," Dermatology, vol. 204, no. Suppl. 1, pp. 70-74, 2002. [Online] Available: http://dx.doi.org/10.1159/000057729
[68] G. C. Yalanis, E.-W. Liu, and H.-T. Cheng, "Efficacy and safety of povidone-iodine irrigation in reducing the risk of capsular contracture in aesthetic breast augmentation," Plastic and Reconstructive Surgery, vol. 136, no. 4, pp. 687-698, oct 2015. [Online]. Available: http://dx.doi.org/10.1097/PRS.0000000000001576

[69] R. Niedner, "Cytotoxicity and sensitization of povidone-lodine and other frequently used anti-infective agents," Dermatology, vol. 195, no. 2, pp. 89-92, 1997. [Online]. Available: http://dx.doi.org/10.1159/000246038

[70] X. jun Zhang, D. L. Chinkes, V. M. S. Ramanujam, and R. R. Wolfe, "Local injection of insulin-zinc stimulates DNA synthesis in skin donor site wound," Wound Repair and Regeneration, vol. 15, no. 2, pp. 258-265, mar 2007. [Online]. Available: http://dx.doi.org/10.1111/j.1524-475X.2007.00213.x

[71] J. Wilson, R. Baines, E. Babu, and C. Kelley, "A role for topical insulin in the management problematic surgical wounds," The Annals of The Royal College of Surgeons of England, vol. 90, no. 2, pp. 160-160, mar 2008. [Online]. Available: http://dx.doi.org/10.1308/003588408X261816

[72] O. Rezvani, E. Shabbak, A. Aslani, R. Bidar, M. Jafari, and S. Safarnezhad, "A randomized, double-blind, placebo-controlled trial to determine the effects of topical insulin on wound healing," Ostomy Wound Manage, vol. 55, no. 8, pp. 22-8, 2009.

[73] S. Greenway, L. Filler, and F. Greenway, "Topical insulin in wound healing: a randomised, double-blind, placebo-controlled trial," Journal of Wound Care, vol. 8, no. 10, pp. 526-528, nov 1999. [Online]. Available: http://dx.doi.org/10.12968/jowc.1999.8.10.26217

[74] B. Bernstein and H. Tam, "Combination of subatmospheric pressure dressing and gravity feed antibiotic instillation in the treatment of postsurgical diabetic foot wounds: a case series," Wounds, p. 37-48, 2005

[75] A. Gabriel, K. Kahn, and R. Karmy-Jones, "Use of negative pressure wound therapy with automated, volumetric instillation for the treatment of extremity and trunk wounds: clinical outcomes and potential cost effectiveness," Eplasty, vol. 14, p. e41, 2014.

[76] M. Leffler, R. Horch, A. Dragu, and U. Kneser, "Instillation therapy and chronic osteomyelitis: Preliminary results with the v.a.c. instill therapy," Infection, vol. 37, p. 24-30, 2009.

[77] M. Schintler, E. Prandl, G. Kreuzwirt, M. Grohmann, S. Spendel, and E. Scharnagl, "The impact of v.a.c. instill in severe soft tissue infections and necrotizing fasciitis," Infection, p. 31-32, 2009.

[78] A. J. Weinstein, "Systemic absorption of neomycin irrigating solution," JAMA, vol. 238, no. 2, p. 152, jul 1977. [Online]. Available: http://dx.doi.org/10.1001/jama.1977.03280020056025

[79] P. A. Netland, J. E. Baumgartner, and B. T. Andrews, "Intraoperative anaphylaxis after irrigation with bacitracin: Case report," Neurosurgery, vol. 21, no. 6, pp. 927-928, apr 1987. [Online]. Available: http://dx.doi.org/10.1227/00006123-198712000-00026

[80] J. Sprung, H. K. Schedewie, and J. P. Kampine, "Intraoperative anaphylactic shock after bacitracin irrigation," Anesthesia \& Analgesia, vol. 71, no. 4, p. 430???433, oct 1990. [Online]. Available: http://dx.doi.org/10.1213/00000539-199010000-00021

[81] D. J. Eedy, J. C. McMillan, and E. A. Bingham, "Anaphylactic reactions to topical antibiotic combinations." Postgraduate Medical Journal, vol. 66, no. 780, pp. 858-859, oct 1990. [Online]. Available: http://dx.doi.org/10.1136/pgmj.66.780.858

[82] J. D'AURIA, S. LIPSON, and J. M. GARFIELD, "Fatal iodine toxicity following surgical debridement of a hip wound: Case report," The Journal of Trauma: Injury, Infection, and Critical Care, vol. 30, no. 3, pp. 353-355, mar 1990. [Online]. Available: http://dx.doi.org/10.1097/00005373-199003000-00019

[83] M. M. Bassan, M. Dudai, and O. Shalev, "Near-fatal systemic oxygen embolism due to wound irrigation with hydrogen peroxide,' Postgraduate Medical Journal, vol. 58, no. 681, pp. 448-450, jul 1982 [Online]. Available: http://dx.doi.org/10.1136/pgmj.58.681.448

[84] A. Gabriel, "Integrated negative pressure wound therapy system with volumetric automated fluid instillation in wounds at risk for compromised healing," International Wound Journal, vol. 9, pp. 25-31, jun 2012. [Online]. Available: http://dx.doi.org/10.1111/j.1742-481X. 2012.01014.x

[85] M. D’Hondt, A. D'Haeninck, L. Dedrye, F. Penninckx, and R. Aerts, "Can vacuum-assisted closure and instillation therapy (VAC-instill $\mathbb{R}$ therapy) play a role in the treatment of the infected open abdomen?" Tech Coloproctol, vol. 15, no. 1, pp. 75-77, jan 2011. [Online]. Available: http://dx.doi.org/10.1007/s10151-010-0662-4 